\title{
Infarto esplénico secundario a pancreatitis aguda
}

\author{
J. J. Arenal Vera, A. Said, J. A. Guerro ${ }^{1}$, M. Otero ${ }^{1}$ e I. Gil ${ }^{2}$ \\ Servicios de Cirugía, 'Radiología y ${ }^{2}$ Medicina Interna. Hospital de Medina del Campo. Valladolid
}

\section{RESUMEN}

Fundamento y objetivo: la estrecha relación anatómica del páncreas con los vasos esplénicos y el bazo es responsable de complicaciones esplénicas en el curso de la pancreatitis aguda. El objetivo es presentar dos casos clínicos de pancreatitis aguda grave que sufrieron infarto esplénico como complicación de la enfermedad pancreática.

Pacientes, participantes: en un periodo de tres meses, dos pacientes fueron diagnosticados de infarto esplénico secundario a pancreatitis aguda. En ambos casos el diagnóstico y seguimiento evolutivo del infarto esplénico se hizo a través de tomografía axial computerizada.

Resultados: en el primer paciente, las imágenes muestran de forma inequívoca la afectación de la arteria esplénica por el proceso inflamatorio pancreático. En el segundo, no se pudo demostrar afectación de los vasos esplénicos, por lo que la única posible explicación etiológica es un incremento de coagulabilidad intravascular.

Conclusiones: sería recomendable añadir las complicaciones esplénicas al conjunto de complicaciones graves extrapancreáticas de la pancreatitis aguda. La tomografía axial computerizada es de gran utilidad para la detección y seguimiento de las complicaciones esplénicas de la pancreatitis aguda.

Palabras clave: Infarto esplénico. Pancreatitis aguda. Estenosis de arteria esplénica.

\begin{abstract}
Background and objective: the close anatomic relationship of the pancreas with the splenic vessels and the spleen is responsible for splenic complications in the course of acute pancreatitis. Our objective was to report two cases of severe acute pancreatitis complicated by splenic infarction.

Patients: in a three-month period of time two patients were diagnosed with splenic infarction secondary to acute pancreatitis. In both cases splenic infarction diagnosis and follow-up were carried out using computed tomography.

Results: in the first case images clearly showed a narrowing of the splenic artery due to the inflammatory pancreatic condition. In the second case no involvement of the splenic vessels could be demonstrated, hence the only possible etiological explanation was a hypercoagulability state generated by pancreatitis.

Conclusions: it would be advisable that splenic complications were added to the list of relevant extrapancreatic manifestations. $\mathrm{CT}$ is very useful for the diagnosis and follow-up of splenic complications arising in acute pancreatitis.
\end{abstract}

Key words: Splenic infarction. Acute pancreatitis. Stenosis of the splenic artery.

Arenal Vera JJ, Said A, Guerro JA, Otero M, Gil I. Infarto esplénico secundario a pancreatitis aguda. Rev Esp Enferm Dig 2008; 100: 300-303.

\section{INTRODUCCIÓN}

El páncreas es un órgano retroperitoneal íntimamente relacionado con vasos esplénicos. Esta estrecha relación anatómica es causa de afectación de los mismos y del bazo en los procesos inflamatorios, tanto agudos como

Recibido: 20-11-07.

Aceptado: 21-11-07.

Correspondencia: Juan J. Arenal. Plaza de Poniente, 2, 3․ 47003 Valladolid. e-mail: jujoarve@yahoo.com crónicos, del páncreas. Uno de los posibles mecanismos de la necrosis pancreática pudiera ser la obstrucción microvascular causada por cambios vasculares espásticos e incremento de la coagulabilidad intravascular (1-3). Estas complicaciones vasculares pueden ocurrir también en otros órganos si el insulto es de suficiente intensidad. Así, se han descrito complicaciones vasculares en la pancreatitis aguda, necrosis renal cortical, infarto esplénico, cardiopatía isquémica, isquemia cerebral e infarto de la retina. Las complicaciones esplénicas en la pancreatitis aguda (trombosis de la vena esplénica, pseudoquiste, ro- 
tura, infarto, necrosis, hematoma y hemorragia por erosión de los vasos esplénicos) aunque poco frecuentes son amenazantes para la vida de los pacientes. Se presentan dos casos clínicos de pancreatitis grave que sufrieron infarto esplénico como complicación de la enfermedad pancreática.

\section{RESULTADOS}

\section{Caso 1}

Varón de 83 años de edad, con antecedentes de hipertensión arterial, hiperuricemia, enfermedad pulmonar obstructiva crónica, divertículo esofágico de tercio medio, hemorragia digestiva por ulcus duodenal, ictus isquémico con paresia de extremidad superior derecha y tratamiento anticoagulante por fibrilación auricular, que ingresa de urgencia por cuadro de dolor continuo en epigastrio acompañado de náuseas sin vómitos. En el examen físico se aprecia pulso arrítmico, roncus en bases pulmonares y abdomen blando no doloroso a la palpación profunda. La analítica en el momento del ingreso era: hematíes 3.830.000; hemoglobina $121 \mathrm{~g} / \mathrm{l}$; hematocrito $37,2 \%$; leucocitos $14,5 \times 10^{\%} / 1$ con $90 \%$ de neutrofilia; creatinina $1,83 \mathrm{mg} / \mathrm{dl}$; urea $74 \mathrm{mg} / \mathrm{dl}$; amilasa en sangre $733 \mathrm{U} / 1$; LDH $495 \mathrm{U} / 1$; tiempo de protrombina $30 \%$; sedimento urinario: piuria moderada y 3-7 leucocitos por campo. Por ecografía abdominal se aprecia aumento de tamaño del cuerpo pancreático y litiasis biliar. Durante siete días se produce incremento paulatino de amilasa en sangre hasta $1.476 \mathrm{U} / 1$, por lo que se practica tomografía axial computerizada de abdomen en la que se aprecia aumento de tamaño de la cola del páncreas, con zona pseudonodular hipodensa, de bordes mal definidos, de 4-5 cm de tamaño, que parece contactar con hilio esplénico y otra imagen hipoecoica de $3 \mathrm{~cm}$ en cabeza de páncreas, sugestivas de pancreatitis aguda con afectación de cabeza y cola del páncreas. Tres días después se practica colangio-pancreatografía retrógrada endoscópica, en la que se aprecia estenosis de papila y presencia de barro biliar en colédoco, realizándose esfinterotomía. A las 24 horas de la esfinterotomía el paciente se queja de dolor en fosa lumbar y costado izquierdos, irradiado a hombro izquierdo, que persiste a pesar de tratamiento analgésico con mórficos, por lo que se practica nueva tomografía axial en la que se aprecia un páncreas irregular, aumentado de tamaño, con exudado peripancreático rodeando la arteria esplénica, que está estenosada, infarto esplénico y derrame pleural izquierdo (Fig. 1), que no se modifican en controles posteriores. A los 40 días del ingreso, el paciente sufre episodio de dolor abdominal difuso, acompañado de sudoración profusa, taquipnea, taquicardia e hipotensión. En la exploración se aprecia distensión abdominal, timpanismo, ausencia de peristaltismo y presencia de heces negras en el tacto rectal

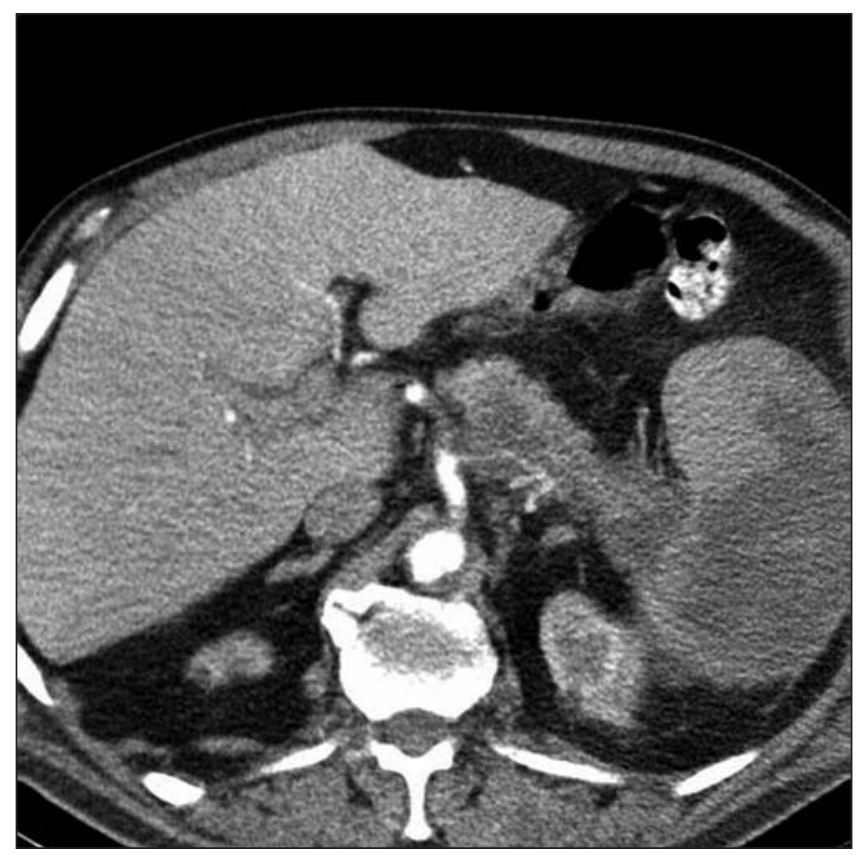

Fig. 1. Estrechamiento de la arteria esplénica a nivel de su origen en el tronco celiaco. Esplenomegalia con infarto esplénico. Páncreas irregular, aumentado de tamaño, con exudado peripancreático rodeando la arteria esplénica.

sospechándose isquemia mesentérica. Exitus a las 12 horas del episodio.

\section{Caso 2}

Mujer de 83 años de edad con antecedentes de histerectomía, cólicos renales, hepatitis $\mathrm{B}$, anemia megaloblástica y cólicos biliares de repetición, que ingresa de urgencia por dolor abdominal difuso, náuseas y vómitos de varios días de evolución. En la exploración abdominal se aprecia dolor a la palpación superficial y profunda en todo el hemiabdomen superior, especialmente en hipocondrio derecho. Analítica al ingreso: 17 x 10\%/1 leucocitos con $86 \%$ de neutrofilia; amilasemia $5.203 \mathrm{U} / 1$; amilasuria $43.703 \mathrm{U} / 1$; LDH $675 \mathrm{U} / \mathrm{l}$; bilirubina total 1,55 mg/dl; GOT 111 U/L; GPT 152 U/l; GGT 203 U/1; PH 7.222, $\mathrm{PCO}_{2} 28,8 \mathrm{mmHg} ; \mathrm{PO}_{2} 80 \mathrm{mmHg}$; bicarbonato 13,7 $\mathrm{mmol} / \mathrm{l}$; fosfatasa alcalina y estudio de coagulación normales. A las 48 horas del ingreso mantiene cifras similares de amilasemia y amilasuria con alteraciones graves de la coagulación: tiempo de protrombina 50\%; tiempo de cefalina 48,2 s. Por tomografía axial computerizada del abdomen se aprecia: colecistitis aguda litiásica, coledocolitiasis, aumento difuso de tamaño del páncreas y ascitis, apreciándose en bazo múltiples áreas de infarto (Fig. 2). A los tres días del ingreso se practica esfinterotomía endoscópica. La paciente evoluciona de forma tórpida, falleciendo a los 17 días por cuadro de shock hemorrágico de origen digestivo. 


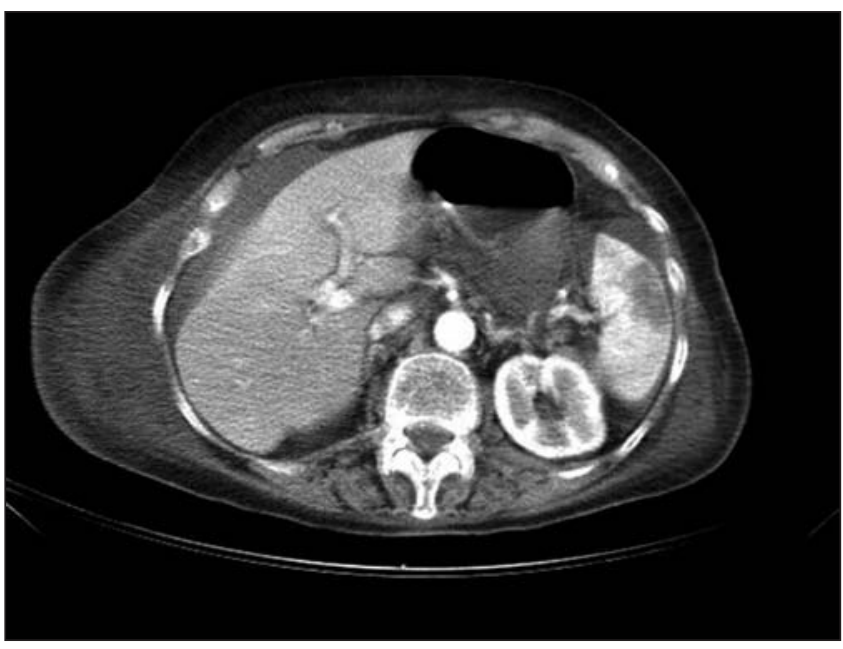

Fig. 2. Edema de tejido subcutáneo. Ascitis. Defecto de perfusión triángular periférico intraesplénico que asocia otras áreas de hipoatenuación de menor tamaño, compatibles con infartos esplénicos.

\section{DISCUSIÓN}

El infarto esplénico es el resultado del compromiso arterial o venoso de los vasos esplénicos, ya sea intraluminal o extraluminal. El 50-72\% de los casos se han descrito asociados a leucemia mieloide crónica y mielofibrosis (4-6). Igualmente se asocia a anemias hemolíticas, estados de hipercoagulabilidad, desórdenes embólicos (fibrilación auricular y endocarditis), enfermedades vasculares, traumatismos, complicaciones quirúrgicas (pancreatectomía y trasplante hepático) y otras causas poco frecuentes como trombosis de la vena esplénica, amiloidosis, sarcoidosis y síndrome de distrés respiratorio del adulto (4-11).

El infarto esplénico secundario a pancreatitis aguda se creía una entidad infrecuente, pero el número de casos publicados parecen indicar una incidencia mayor de la que se pensaba (12-15). Estudios radiológicos retrospectivos han hallado porcentajes de incidencia del $7 \%$, demostrando una correlación de prevalencia, estadísticamente significativa, entre esta complicación y la severidad de la pancreatitis (14).

El espectro clínico varía desde el infarto asintomático al shock hemorrágico secundario a hemorragia subcapsular masiva con rotura libre a la cavidad peritoneal. Un tercio son clínicamente ocultos. El síntoma más común es dolor en hipocondrio izquierdo. Son síntomas adicionales fiebre, escalofríos, náuseas y vómitos, dolor pleurítico y dolor en hombro izquierdo (signo de Kher) $(4,5)$. El principal objetivo del tratamiento médico es la analgesia con narcóticos o antiinflamatorios no esteroideos. La cirugía sólo está indicada en caso de complicaciones. En general, la mayoría de los infartos esplénicos no requieren tratamiento quirúrgico. Las indicaciones de tratamiento quirúrgico son: sepsis, absceso, hemorragia y formación de pseudoquiste (5). El pronóstico varía en relación al proceso responsable del infarto esplénico.
Se han descrito varios mecanismos por los que se produciría el infarto esplénico en el curso de la pancreatitis aguda. El más frecuentemente invocado es la trombosis de la vena esplénica, ya sea por extensión directa del proceso inflamatorio local, por hipercoagulabilidad inducida por la pancreatitis o por ambos (1). También se ha descrito la compresión directa de los vasos esplénicos e incluso del parénquima esplénico por un pseudoquiste de la cola pancreática como responsables de infarto del bazo (2). La compresión de la arteria esplénica, la afectación de la pared de la misma por el proceso inflamatorio o un espasmo arterial permanente podrían ser otros mecanismos de desarrollo de infarto esplénico. Estudios angiográficos en pacientes con pancreatitis aguda han detectado cambios isquémicos como espasmo difuso y obstrucción de grandes vasos esplácnicos, incluida la arteria esplénica, en el $41 \%$ de los casos, cuya incidencia estaba estrechamente relacionada con la gradación de Ranson (3).

En el primer caso descrito, la estenosis de la arteria esplénica demostrada en la TAC, debida a cambios inflamatorios en las paredes de la misma, o a compresión directa por el tejido pancreático inflamado, parece el mecanismo responsable del desarrollo del infarto esplénico. La posibilidad, en este paciente, de un origen embólico secundario a la fibrilación auricular como causa de la pancreatitis y del infarto esplénico, hipótesis ya descrita en la literatura $(9,10)$, es improbable. Esta improbabilidad está basada en la anticoagulación del paciente, el análisis de las imágenes tomográficas y la presencia de enfermedad litiásica biliar como responsable etiológico de la pancreatitis. En el segundo caso es aventurado establecer hipótesis alguna. No obstante, ante la falta de evidencia de afectación de los vasos esplénicos, cabría pensar en un aumento de la coagulabilidad intravascular como factor desencadenante de las múltiples áreas de infartación. La demora en acudir al hospital no ha permitido un estudio evolutivo, como en el primer caso, siendo diagnosticado el infarto esplénico el mismo día del ingreso.

En base al conocimiento actual, parece recomendable añadir las complicaciones esplénicas al conjunto de complicaciones graves extrapancreáticas de la pancreatitis aguda como el shock, fallo respiratorio, renal, coagulopatías, etc., y prestar mayor atención a los posibles cambios del bazo en este contexto. La tomografía axial computerizada es de gran utilidad para la detección y seguimiento de las complicaciones esplénicas de la pancreatitis aguda.

\section{BIBLIOGRAFÍA}

1. Cornu-Labat G, Karthikeshwar K, Simon R, Smith DJ, Herman ML, Rubin JR. Acute mesenteric vein thrombosis and pancreatitis. Int J Pancreatol 1997; 21: 249-51.

2. Collie DA, Ferguson JM, Allan PL, Redhead DN. Case report: Computed tomography features of complete splenic infarction, cavitation and spontaneous decompression complicating pancreatitis. $\mathrm{Br} \mathrm{J}$ Radiol 1995; 68: 662-4. 
3. Inoue K, Hirota M, Beppu T, Ishiko T, Kimura Y, Maeda K, Ogawa M. Angiographic features in acute pancreatitis: The severity of abdominal vessel ischemic change reflects the severity of acute pancreatitis. JOP 2003; 4: 207-13.

4. Nores M, Phillips EH, Morgenstern L, Hiatt JR. The clinical spectrum of splenic infarction. Am Surg 1998; 64: 182-8.

5. Jaroch MT, Broughan TA, Hermann RE. The natural history of splenic infarction. Mt Sinai J Med 1997; 64: 342-9.

6. Frippiat F, Donckier J, Vandenbossche P, Stoffel M, Boland B, Lambert M. Splenic infarction: Report of three cases of atherosclerotic embolization in the aorta and retrospective study of 64 cases. Acta Clin Belg 1996; 51 (6): 395-402.

7. Gázquez I, Vicente de Vera P, García MJ, López A. Infartos esplénicos y hematoma subcapsular en el curso de una pancreatitis crónica (carta). Med Clin (Barc) 2003; 120: 599

8. Fatjo F, Ramos J, Culla A, Grau JM. Splenic infarctions: An uncommon cause of fever. Med Clin (Barc) 2002; 119: 357-8.

9. Muñoz Ruiz AI, Guerrero Vega E, García Flores S, de Tena-Dávila Ruiz M, Marcos Sánchez F, Durán Pérez-Navarro A. Splenic infarction as a complication of atrial fibrillation. Rev Esp Enferm Dig 2003; 95: 66-7.

10. Janowitz P, Von Moltke A, Weidmann B. Acute pancreatitis caused by atrial fibrillation? Dtsch Med Wochenschr 2002; 127: 2669-72.

11. Unstun C, Kutlar F, Holley L, Seigler M, Burgess R, Kutlar A. Interaction of sickle cell trait with hereditary spherocytosis: Splenic infarcts and sequestration. Acta Hematol 2003; 109: 46-9.

12. Lankisch PG. The spleen in inflammatory pancreatic disease. Gastroenterology 1990; 98: 509-16.

13. Ripens F, Deviere J, Braude P, Van de Stadt J, Struyven J, Van Gansbeke D. Splenic parenchymal complications of pancreatitis: CT findings and natural history. J Comput Assist Tomogr 1997; 21 : 89-93.

14. Mortele KJ, Mergo PJ, Taylor HM, Ernst MD, Ros PR. Splenic and perisplenic involvement in acute pancreatitis: Determination of prevalence and morphologic helical CT features. J Comput Assist Tomogr 2001; 25: 50-4.

15. Fishman EK, Soyer P, Bliss DF, Bluemke DA, Devine N. Splenic involvement in pancreatitis: Spectrum of CT findings. Am J Roentgenol 1995; 164: 631-5. 